\title{
A busca por inovação através de decisões estratégicas baseadas em métricas de audiência: os casos de GaúchaZH e Folha de S.Paulo Maria Clara Aquino Bittencourt e Greyce Vargas
}

\section{Resumo}

Este artigo apresenta parte dos resultados de uma pesquisa que buscou entender as decisões estratégicas das empresas GaúchaZH e Folha de S. Paulo, que são afetadas pelas métricas de audiência. Setores específicos são identificados nas duas empresas, responsáveis por gerir métricas e originar decisões a partir dos comportamentos dos usuários, orientando resoluções de negócios desde a produção jornalística. Apresentamos parte dos resultados da investigação sobre esses setores, já que são responsáveis pela deliberação de problemas e exploração de novas oportunidades com base nas métricas que gerenciam e com foco na inovação.

\section{Palavras-Chave}

Inovação. Audiência. Jornalismo.

\section{Maria Clara Aquino Bittencourt}

Docente e pesquisadora no Programa de Pós-Graduação em Ciências da Comunicação da Universidade do Vale do Rio dos Sinos - Unisinos, São Leopoldo, Rio Grande do Sul, Brasil. E-mail: aquino.mariaclara@gmail.com.

https://orcid.org/0000-0001-8230-5921

\section{Greyce Vargas}

Mestranda no Programa de Pós-Graduação em Ciências da Comunicação da Universidade do Vale do Rio dos Sinos Unisinos, São Leopoldo, Rio Grande do Sul, Brasil. E-mail: greycevargas@gmail.com

\section{Introdução}

Muitas empresas de jornalismo têm concentrado a atenção em resultados da audiência para repensar estruturas de redação e estratégias de inovação. Empresas que trabalham com a ideia de digital first ${ }^{1}$ usam os resultados de audiência para tentar inovar e driblar dificuldades financeiras. Nos últimos dois anos, realizamos uma pesquisa cujos resultados mostram-nos como a busca por inovação na gestão e nas práticas jornalísticas guiam as ações estratégicas de GaúchaZH e Folha de S.Paulo. Analisando essas empresas, recuperamos a reestruturação de suas redações em função da internet - e como ainda continuam nesse processo de redesenho organizacional.

Esse movimento de reorganização interna é estratégico para o jornalismo enquanto negócio. Ao mesmo tempo, percebe-se que 0 comportamento dos usuários transformou-se na base das estratégias de inovação. Investe-se em mídias móveis porque os usuários consomem mais notícias por meio de seus smartphones e tablets. Haak, Parks e Castells (2012) chamam 
o momento atual de jornalismo em rede, referindo-se ao modelo como aquele em que as empresas do setor têm capacidade para registrar informações, compartilhar e distribuir conteúdo. Heinrich (2011) salienta que o conceito de jornalismo em rede não pode ser confundido apenas com inovações tecnológicas aplicadas à produção. 0 jornalismo em rede incorpora redes multiplataformas em diferentes estágios do processo de produção de notícias, alterando, portanto, toda a cadeia da prática. 0 conceito dá conta da reconfiguração que ocorreu nas relações entre repórteres e fontes, da integração de conteúdo gerado por usuários, da interação em plataformas multimídia, das novas formas de conexão entre jornalistas dentro da mesma redação e de um modelo estrutural do ambiente jornalístico, no qual as organizações funcionam como nós de informação (HEINRICH, 2011).

Empresas que são digitais desde sua origem, e cuja estratégia original visa à cultura participativa e interativa, apresentam mais flexibilidade de adaptação no mercado jornalístico atual. Empresas tradicionais, -que originalmente não iniciariam suas atividades em moldes digitais e tiveram que aprender e se adaptar aos impactos da cultura da convergência midiática e jornalística, enfrentam um pouco mais de dificuldade e alguns obstáculos nessa caminhada (JENKINS, 2006; SALAVERRÍA, 2009). Um exemplo são os resultados da circulação dos jornais ditos tradicionais. No primeiro semestre de 2016, as quedas de Folha de S.Paulo, 0 Globo, Super Notícia, Zero Hora (do qual GaúchaZH faz parte) e 0 Estado de S. Paulo ficaram entre $8 \%$ a $15 \%$ negativos, segundo o Índice Verificador de Comunicação (IVC) . 0 estudo Digital News Report 2017 aponta que, em dezembro de 2016, "a circulação total dos cinco melhores jornais pagos caiu quase $8 \%$ em relação ao número médio de cópias vendidas em 2015" (CARR0, 2017, p. 105). 0 número de assinantes de jornais digitais entre 2015 e 2016, de acordo com o levantamento da Reuters, manteve-se em $22 \%$.

A maior parte das empresas de jornalismo que nasceram antes da internet não conseguiram acompanhar a mudança de comportamento das audiências. Mudar de notícias impressas para notícias digitais, explica Kung (2015, p. 16), equivale a "fechar os estábulos, vender os cavalos e comprar uma ferrovia. Um negócio completamente diferente". Os jornais impressos agora entendem isso, mas concorrem hoje com quem tem modelos de negócio considerados inovadores e produtos muito parecidos, mas a preço zero ao consumidor. A consequência disso aparece diretamente nos problemas estratégicos dessas organizações que foram criadas antes da internet. Sem saber como voltarem a lucrar, muitas acabaram produzindo 
conteúdos em favor dos números de audiência e caíram em superficialidade (SALAVERRÍA, 2015), por exemplo.

Graves e Kelly (2014) explicam que o impacto da audiência tem participado dos critérios de noticiabilidade. Canavilhas (2016, p. 2) assinala que a notícia foi impactada por informações que vão além dos fatos apurados já que os tecnoatores que atuam hoje nas redações alteram a estrutura básica da produção. Isso se dá porque esses sujeitos têm "profundo domínio técnico sobre linguagens de programação e softwares de edição que agem sobre 0 trabalho jornalístico, influenciando simultaneamente os procedimentos e os produtos".

\section{GaúchaZH e Folha de S.Paulo passaram por}

alterações estruturais importantes nos últimos anos, baseadas em estudos de métricas de audiência que marcaram a mudança estratégica das empresas para voltarem seus negócios para o jornalismo na internet. A escolha das duas organizações revela dois modelos de negócio que representam um panorama do cenário atual do jornalismo no país. GaúchaZH é o nome do produto digital que marca a integração das redações de Zero Hora e Rádio Gaúcha, empresas do Grupo RBS, de Porto Alegre, e a mudança estratégica do negócio jornalismo da empresa. Partiu-se, portanto, do comportamento da audiência medida por meio do Google Analytics para a transformação cultural com o propósito de, novamente, reorganizar o produto jornalismo e a redação, culminando na virada estratégica de 2017. Em 2015, a Folha também fez uma virada estratégica com base em métricas. 0 setor de audiência foi reformulado e passou a fazer pesquisas sobre o comportamento dos leitores, a partir das métricas de acesso, para rever a estratégia de conteúdo.

Dessa forma, a pesquisa teve como principal questão entender as decisões estratégicas das empresas GaúchaZH e Folha de S.Paulo que são afetadas pelas métricas de audiência. Entendemos as métricas de audiência como as medições feitas por ferramentas, como o Google Analytics e o Chartbeat, que são utilizadas por redações de empresas jornalísticas para monitorar o percurso dos usuários em sites que utilizam tais ferramentas para observar, por exemplo, número de acessos, páginas e notícias mais acessadas, tempo de permanência nas reportagens e matérias, número de usuários únicos, número de páginas e matérias mais acessadas, entre outras possibilidades de avaliação. Esse tipo de métrica certamente interfere no desempenho da atividade dos jornalistas que atuam nas redações e que utilizam essas ferramentas, considerando que suas atividades podem ser avaliadas e balizadas pelo empregador a partir dos resultados fornecidos pelos recursos que fornecem as métricas de audiência.

Entendemos, também, que um dos principais objetivos no processo de medição de audiência no jornalismo na internet é 0 engajamento. 
É isso que tem sustentado algumas mídias digitais e é isso que motiva mudanças e reestruturações nas empresas jornalísticas. 0 engajamento está diretamente ligado ao comportamento da audiência porque essa métrica é o resultado do tempo de permanência de consumo de um usuário sobre um conteúdo, somado à forma como o usuário chegou ao conteúdo e à recirculação que ele dará ao produto noticioso. Se um conteúdo circula, então pode/deve haver investimento em torno dele. No atual contexto - em que "a circulação de conteúdo de mídia dentro da cultura participativa pode servir a uma variedade de interesses, alguns deles culturais, outros pessoais ou políticos e econômicos" (JENKINS, FORD E GREEN, 2014, p. 62), ou todos ao mesmo tempo -, no âmbito do jornalismo, a premissa não pode ser desconsiderada. Hoje, editores lidam e negociam com os dados da audiência em tempo real, o que vai implicar diretamente a produção por meio das ferramentas que medem a audiência, como Google Analytics e Chartbeat.

Nos dois jornais analisados, foram adotados, a partir dessa negociação em tempo real, relatórios de produtividade por meio do resultado de audiência, o que acabou se tornando uma via para decidir sobre novos cargos, fechamento de vagas e reorganização do escopo de tarefas de cada profissional na redação, conforme vimos nas entrevistas.

Sendo assim, movidas a partir da pergunta central, sobre como as decisões estratégicas são afetadas pelas métricas de audiência, encontramos, dentro das empresas, setores específicos que cuidam dessas métricas e originam decisões a partir dos comportamentos dos usuários, orientando decisões de negócios. Neste artigo, nosso objetivo é apresentar parte da investigação que fizemos nestes dois anos sobre esses setores, já que são departamentos que resolvem problemas e exploram oportunidades com base nas métricas que coletam. Estruturamos o texto a partir da contextualização teórica sobre a noção de convergência de métricas, para em seguida abordar a relação entre métricas e inovação. 0 quarto item apresenta, brevemente, a abordagem metodológica e analítica da pesquisa, destacando estruturas de gestão de audiência das duas empresas analisadas: GaúchaZH e Folha de S.Paulo. Por fim, apontamos problemas e dificuldades dos modelos adotados, concluindo o texto com apontamentos que recuperam parte das referências nas quais nos apoiamos nas fases iniciais do estudo.

\section{Audiência, jornalismo e convergência de métricas}

A audiência hoje tem papel social diferente do que tinha em outros períodos do jornalismo, em que influenciava o modo de fazer jornalismo. Como explicam Canavilhas, Torres e Luna (2016, p. 141), "ao determinar a visibilidade da notícia", a audiência está assumindo "o papel de editor de conteúdos, embora fora da instituição jornalística", e isso 
dá "autoridade editorial" a ela "em relação aos conteúdos que circulam dentro da sua comunidade de referência nas redes sociais".

Não se trata de trazermos aqui uma recuperação bibliográfica ampliada sobre os estudos de audiência, mas é importante apontar que há uma trajetória anterior que revela como se construiu um entendimento sobre a transformação de um receptor passivo para um receptor ativo. No âmbito de um conjunto de teorias que, no início do século XX, por exemplo, abordavam apenas mensuração de índices, e que, com o passar dos anos, foram incorporando elementos de outros campos, como a psicologia e a sociologia, foram elaboradas bases para se pensar que os indivíduos são capazes de responder aos estímulos midiáticos de forma ativa e crítica. Isso constituiu, portanto, a noção de audiência como algo que acabou se fortalecendo como objeto de estudo no campo da comunicação e, consequentemente, do jornalismo. Com 0 avanço tecnológico, a problematização da audiência tornou-se ainda mais latente, diante da proliferação de ferramentas de comunicação digital, sites de redes sociais, aplicativos e plataformas em rede, entre outros, por meio dos quais o conteúdo jornalístico circula e é apropriado e (re)circulado pelas audiências.

No contexto desta investigação, o usuário que replica ou produz conteúdo nas redes digitais, por exemplo, pode ter sua própria audiência e se preocupa com o engajamento e com sua reputação. Isso é poder - principalmente porque o sujeito é audiência e tem audiência fazendo frente às empresas de mídia. Isso vai ao encontro do que explica Jenkins (2014, p. 153), de que "audiência é uma cooperativa de agentes ativos cujo trabalho pode gerar novas alternativas de valor de mercado (...)propensa a recomendar, discutir, pesquisar, repassar e até gerar material novo" (2014, p. 153). Ainda assim, "a indústria busca membros da audiência que se encaixem nos mercados específicos, definidos por dados demográficos de idade e sexo que sejam desejáveis para os anunciantes" (Obra citada, p. 150). Podemos dizer, com isso, que a atenção da audiência é commodity e que o engajamento tem alto valor no mercado, e, ainda que seu comportamento possa ser medido, não se trata de uma massa. 0 engajamento pode ser explicado pela convergência (tecnológica, mercadológica, cultural, social). No caso do jornalismo, Jenkins (2009) diz que, agora, os consumidores de notícias não apenas podem como são incentivados a procurar novas informações e a fazer conexões que vão resultar em engajamento e em alcance do produto jornalístico.

Com os anos, o que vem mudando é a potencialidade de como as pessoas compartilham conteúdo. A audiência já foi compreendida como passiva, mas estudos mostram que ela sempre, de alguma forma, interagiu com o conteúdo, produzindo significado. A evolução do conceito de audiência dá-se no período em que os estudos 
semióticos somam-se aos sobre comunicação, jornalismo, sentido e significado. McQuail (1975 APUD WOLF, 1999, p. 57) explicita isso quando separa o emissor do receptor como conceito, mas relativiza os problemas comuns sobre os dois sujeitos. Segundo o autor, "emissor e receptor têm, um do outro, uma imagem que eles próprios constroem, modificam e a que atribuem importância", mas "fazem-no de uma forma um tanto autista, sem grande referência ao outro e tendem a cair nos estereótipos, o destinador com um estereótipo do público e o destinatário com imagens estereotipadas daquilo que se deve esperar dos mass media".

Ao dialogar sobre quem é a audiência hoje, Jenkins (2006) leva em conta a ideia de inteligência coletiva pensada por Lévy (1993) e a cultura da participação no contexto da cultura da convergência. Em 2006, Jenkins situava a audiência como um público que tem o poder de gerar novos significados sobre mensagens, mercados, meios de circulação, produções, podendo interromper e reformatar operações de cultura contemporânea enquanto essas coisas todas acontecem. 0 autor nos leva por um caminho em que entende a audiência como consumidor, como um dado medido pelas empresas de conteúdo e como um sujeito engajado e ativo diante das informações. Entende que 0 papel das audiências é ativo e consciente, e, junto com Ford e Green (2014), abordam as atividades desses públicos em relação ao conteúdo. É nesse sentido que a audiência transforma o processo de produção de notícias, por exemplo.

Compreender a audiência, obviamente, também culmina em desenvolvimento comercial. A história mostra-nos que o principal efeito da medição de audiência no jornalismo (como é feita hoje) é o engajamento. 0 s efeitos do engajamento da audiência explicam por que o jornalismo na internet mudou de fases tão rápido e em menos de duas décadas. 0 engajamento do leitor e a possibilidade de medir a audiência levou o jornalismo a rever seus valores e suas estratégias. Entender 0 comportamento da audiência é necessidade primária atualmente, e é isso que vai evidenciar o modelo estratégico da produção e apontar o impacto no jornalismo enquanto instituição.

GaúchaZH e Folha de S. Paulo têm semelhanças importantes para 0 contexto deste estudo: ambas investem em jornalismo impresso ao mesmo tempo em que fortalecem as estruturas digitais, usam as mesmas ferramentas de métricas e apostam em paywall poroso $0^{2}$ para acesso às notícias no site - usam a ferramenta Chartbeat para medir a audiência em tempo real na capa do site e, dentro do site, a ferramenta Google Analytics para mostrar comportamento 
da audiência de forma mais ampla. 0 contato com esses dados e essas ferramentas mudou a configuração e o modo de trabalho das redações. Trata-se de ferramentas que dão base, agora, para a tomada de decisões estratégicas que são apresentadas e usadas pela gestão das empresas, por determinados departamentos e pela redação. Podemos dizer, portanto, que estamos vivendo uma fase do jornalismo em que prevalece a convergência de métricas - uma ideia que desenvolvemos a partir de Jenkins (2006), para pensar a noção de convergência de forma mais abrangente, e Salaverría (2003), para tratar do conceito no âmbito do jornalismo.

Os três pontos fundamentais que Jenkins (2006) reúne sobre a convergência são explicativos de seu argumento: 0 fluxo de conteúdo através de múltiplas plataformas, a cooperação de múltiplos mercados e o comportamento migratório dos públicos dos meios de comunicação. Convergência é, portanto, para o autor, um conceito que define transformações que ocorrem nas tecnologias, no mercado, na cultura e na sociedade. Adotamos uma perspectiva sobre a convergência que entende 0 conceito por um viés que avança para além da perspectiva tecnológica, considerando seu viés social e cultural (AQUINO BITTENCOURT, 2017). Nesse sentido, o papel da audiência na constituição do fenômeno é pensado e considerado com base na noção de apropriação, na medida em que seu comportamento é decisivo no processo de circulação. Essa forma de situar a convergência teoricamente na pesquisa permite que se agregue valor ao papel ativo da audiência no processo de circulação das notícias. A conexão ao conceito de engajamento é direta, uma vez que se aciona 0 trabalho com as métricas para a definição de estratégias que mobilizem as audiências nos processos de circulação e consumo dos produtos jornalísticos.

Por convergência jornalística, Salaverría (2003) compreende o processo de integração dos meios de comunicação que afeta as empresas, a tecnologia, os jornalistas, a audiência e, ainda, a produção, a circulação e 0 consumo de conteúdo. A audiência, dentro das redações, segundo Robinson (2016, online), é formada por uma mistura de "experiência, observação e imaginação", que é calculada, de acordo com o que constatamos, por diferentes programas e ambientes digitais. Chartbeat, Google Analytics e sites como o Facebook medem o comportamento da audiência, cada um com suas próprias metodologias, e as empresas jornalísticas compilam os dados a fim de moldá-los conforme suas estratégias. Cria-se aí o que estamos chamando de convergências de métricas, que pode ser entendida como uma decorrência do que Jenkins e Salaverría tratam.

Convergência de métricas dá conta das competências jornalísticas, analísticas e gestoras de sistemas sobre a audiência de conteúdos na internet. Para ocorrer, é preciso, como explica 
Canavilhas (2016, p. 13), "hibridismo profissional" e mediadores de processos jornalísticos para construir a cultura ideal em direção à estratégia desenhada pelas empresas. Com isso, as análises sobre os dados do comportamento da audiência sobre os conteúdos podem participar da renegociação e mudanças nas regras, rotinas e normas jornalísticas. (TANDOC Jr. 2013, p. 16). Isso fica claro quando Petre (2015) mostra-nos como a decisão editorial e estratégica é afetada pela gestão de métricas de audiência. Podemos apontar que a convergência de métricas levanta, portanto, questões fundamentais sobre o jornalismo, do propósito ao significado.

Entendemos que esse conceito explica 0 comportamento, a medição, a análise e a tomada de decisões no jornalismo vinculadas ao processo de jornalismo na internet. Outro ponto que está dentro da ideia de convergência de métricas é que o resultado do comportamento da audiência não é uma matemática sólida, com números que resolvem as questões analíticas, que podem embasar decisões. Para o autor, métricas são moldadas pela produção, pela cultura da empresa: "Esforços para entender as formas como as métricas estão mudando o jornalismo devem ter em mente que 0 inverso também pode ser verdade" (PETRE, 2015, p. 48). A convergência de métricas é, portanto, o resultado do comportamento do leitor/consumidor, por meio de diferentes recursos, moldada por quem tem acesso a elas, manipulada por diferentes equipes.
Essa conjunção formará valores que vão impactar estratégias de negócio, que vão interferir nas práticas jornalísticas, do desenho da redação à circulação de notícias e que vão permitir uma maior colaboração entre fornecedores de conteúdo e patrocinadores para que o produto final seja moldado conforme a audiência interage (JENKINS, 2006). Isso teve efeito direto na estrutura das empresas tradicionais, como pudemos ver em Folha de S.Paulo e GaúchaZH, cujas equipes estão sendo realinhadas para que a produção possa se comportar conforme a audiência. 0 que a convergência de métricas nos dois jornais nos revela é que 0 comportamento da audiência mostra que o consumidor tem muita informação disponível e faz vínculos/conexões entre os conteúdos. Isso pode ser percebido quando analisamos os conteúdos mais lidos e recirculados. 0 leitor comporta-se, dentro dos sites, especificamente, conforme as informações prévias que 0 levou até ali e parte para o consumo e a distribuição do conteúdo conforme 0 seu gosto. Com isso, mostra aos jornais, por meio dos rastros que foram captados pelas ferramentas de métricas, quais são seus gostos, seu tempo disponível e 0 engajamento com o conteúdo e com a marca.

\section{Métricas e inovação}

As métricas sobre o comportamento do usuário podem ser consideradas um tipo inovação que se tornou um processo que acabou abrindo espaço para outros processos de inovação dentro das redações tradicionais. Foi por meio 
da análise do comportamento dos usuários em diferentes ambientes que The New York Times (2014), por exemplo, percebeu que, embora estivesse produzindo conteúdo jornalístico de qualidade, não estava alcançando e impactando os leitores na era digital. As dificuldades que o jornal encontrou não são diferentes do que muitos jornais tradicionais brasileiros (e de outros países) enfrentam. 0 relatório provocou a reflexão sobre gestão e organização interna em muitas empresas jornalísticas, fazendo com que setores e equipes passassem a pensar a inovação nas redações.

Haddad (2010, p. 31) explica que inovação é resultado de iniciativas na busca por um objetivo específico, "que impactam a reorganização das atividades econômicas. A inovação é senão a necessidade de destruição das estruturas econômicas já existentes para possibilitar a criação de novas estruturas". Ouden (2012, p. 61) indica que, hoje, inovações são caracterizadas por mudanças que assimilam diferentes níveis de valores em benefício da sociedade. "As inovações que buscamos precisarão abordar 0 comportamento do usuário, mas também poderão afetar as estruturas atuais no ecossistema." ${ }^{3}$. Por isso, uma inovação não necessariamente necessita de uma invenção. Segundo a autora, basta uma mudança que tenha repercussão nos usuários, na própria empresa, no ecossistema da organização e na sociedade. Ouden (2012, p. 62) diz que, com isso, inovação representa mudança "econômica (preço), funcional (soluções), emocional (experiência) e simbólica (significado)"4. Inovações, desse modo, são capazes de mudar todo o ecossistema. 0 The New York Times, quando passa a rever a estratégia a partir dos dados de audiência, é visto pelo mercado como uma empresa ousada. Quando os resultados começam a aparecer, boa parte do mercado começa a seguir caminhos parecidos, adaptando os processos da empresa que inovou conforme seus propósitos. Foi o que GaúchaZH e Folha de S.Paulo fizeram ao criar ambientes de inovação para entender como os usuários se comportam, o que querem e como são capazes de entender e ressignificar os valores propostos.

Quando nos propusemos a entender as decisões estratégicas das empresas GaúchaZH e Folha de S.Paulo que são afetadas pelas métricas de audiência, deparamo-nos com setores específicos que dão conta das métricas e originam essas decisões orientadas pelo comportamento dos usuários. Esses setores propõem transformações no negócio a partir da produção jornalística. A esse ambiente, Salaverría (2015a, p. 398) chama

Tradução nossa para "The innovations we are aiming for will need to address user behavior, but are also likely to disrupt the current structures in the ecosystem."

Tradução nossa para "economic (price); functional (solutions); emotional (experience); and symbolic (meaning)". 
de "labs". São, segundo o autor, "departamentos destinados a pesquisar sobre avanços tecnológicos e a impulsionar a inovação em suas organizações”. Podemos dizer que os setores que tratam de métricas nas redações de GaúchaZH e Folha de S.Paulo não se originaram com o intuito de inovar, mas hoje têm a inovação como um de seus compromissos. São departamentos que tratam de melhorar produtos e serviços com base nos dados sobre o comportamento do usuário.

Os departamentos de GaúchaZH e Folha de S.Paulo que apoiam decisões estratégicas com base em métricas encaixam-se no modelo que 0 autor chama de inovações de processo. A denominação deve-se ao fato de usarem suas investigações para mudar o processo tradicional ao induzirem a novas formas e modelos de trabalho. Assim, essas áreas constituem-se "como novos catalisadores dos processos de inovação" ${ }^{\prime 6}$ nas empresas. (SALAVERRÍA, 2015a, p. 399). Esses departamentos trabalham pela resolução de problemas e exploram oportunidades para as empresas, sempre baseados em métricas. 0s números sobre a audiência é que vão apoiar as decisões sobre as transformações propostas e aplicadas aos processos de produção. São decisões/planos que impõem inovação em linguagens, formatos da notícia, projetos e iniciativas comerciais, conforme lista 0 autor.

Ao buscar entender os "inovadores em jornalismo digital", Kung (2015, p. 1) aponta que "inovação é a nossa condição de sobrevivência. E sobrevivência de jornais é completamente dependente da nossa habilidade de envolver". Trabalhar a estratégia pela audiência requer, portanto, a abertura para a transformação do negócio. Jenkins, Ford e Green (2014) discutem a importância de analisar o engajamento da audiência primeiro pelo digital; afinal os modelos anteriores que apoiavam as decisões estratégicas eram baseados em amostras. A audiência digital localiza o que os autores apontam como "pessoas no fim de uma cadeia de valor, até uma extremidade inoperante" (p. 161) e, com isso, poderão criar e/ou tratar "o produto, o serviço ou a experiência como um ponto de partida" (MCCRACKEN, 2005 APUD JENKINS, FORD E GREEN 2014, p. 162).

Salaverría (2015c, p. 143) ${ }^{8}$ aponta que inovação em jornalismo "é o caminho que os meios

Tradução nossa para "departamentos destinados a investigar sobre la vanguardia tecnológica e impulsar la innovación en sus organizaciones."

Tradução nossa para "nuevos catalizadores de los procesos de innovación en los medios".

Tradução nossa para "Innovation is a condition for our survival. And the survival of newspapers is completely dependent on our ability to evolve."

Tradução nossa para "nuevas formulas editoriales, tecnologías, lenguajes, modos de conectar con el público." 
terão que enfrentar" se quiserem deixar para trás as diferentes crises "e abrir, por fim, uma nova etapa de esperança para o jornalismo". Com isso, podemos dizer que inovar em jornalismo requer proposta de valor e de compreensão sobre o comportamento do consumidor. 0 que estamos avaliando são dois modelos distintos, mas que se assemelham pois pensam na reavaliação da estratégia, na adequação dos propósitos e em mudanças na produção, quando se trata de buscar inovação.

\section{Estruturas de gestão e audiência}

Na tentativa de identificar que decisões estratégicas são afetadas pelas métricas de audiência nos jornais GaúchaZH e Folha de S.Paulo, a construção metodológica foi fragmentada e realizada em quatro fases: pesquisa do estado da arte do campo; pesquisa histórica das empresas a serem analisadas, em conjunto com um exercício exploratório com profissionais de ambas; pesquisa teórica; e, por fim, análise empírica, utilizando técnicas de entrevistas e apoio em relatórios de inovação9

Os relatórios de inovação, feitos pelo The New York Times, Tow Center for Digital Journalism e Reuters Institute for the study of Journalism apontam questões fundamentais para a construção das entrevistas que foram aplicadas com pessoas chave, identificadas nas redações dos jornais analisados, pois entende-se que compreender como trabalhar com e a partir do comportamento medido por ferramentas de métricas é uma forma de inovação no jornalismo tradicional. Esses documentos serviram de aporte para as entrevistas, que realizamos com duas pessoas apontadas como responsáveis pela tomada de decisão sobre métricas dos dois jornais, e apoiaram a construção de categorias de análise. 0s relatórios também foram consultados para constituir o nosso entendimento sobre a ideia de convergência de métricas, pois entendemos que esse conjunto de dados fornece uma perspectiva detalhada da conjuntura histórica e econômica na qual as empresas estão enquadradas. 0 cruzamento das informações contidas nesses relatórios permitiu-nos ter uma percepção mais abrangente sobre 0 mercado jornalístico, indo além do cenário nacional.

\section{OS MODELOS DE FUNCIONAMENTO NAS EMPRESAS ANALISADAS}

\section{Em GaúchaZH, identificamos que a gestão} absorve três estruturas: produto digital, redação e estratégia e desenvolvimento digital. 0 produto digital está diretamente ligado à redação, mas com foco estrito nas plataformas de circulação de conteúdo digital. Atualmente, a redação concentra um número maior de 
atores ligados ao produto digital do que os que trabalham com o produto impresso. 0 processo jornalístico todo é organizado a partir do produto digital, desde a concepção da pauta até a edição do impresso.

\section{A estrutura de estratégia e desenvolvimento} digital não está dentro da redação, mas em um desenho mais próximo da área de marketing na empresa. Dentro dela, está a equipe de gestão e incentivo à audiência, que tem de responder à gerência de produto digital de GaúchaZH, mas também a atores de gestão de produtos digitais de outras marcas dentro da mesma empresa - como rádios de entretenimento, área institucional e área comercial. A parte da equipe responsável pela gestão da audiência dos produtos digitais jornalísticos é formada por analistas de marketing e assistentes de tráfego e processos. Esses atores não são jornalistas, têm formações em publicidade, análise de sistemas, design e marketing. Ainda assim, respondem por toda a análise do comportamento da audiência de produtos jornalísticos, apontando demandas, falhas, acertos e possibilidades de novos ou remodelação de processos. Há uma distância não apenas física, mas de valores entre as estruturas. Embora a redação tenha passado por um processo de integração, ainda existem fronteiras que parecem impor barreiras à cultura digital na empresa. Tais distâncias, como explicam Canavilhas et.al. (2016), acentuam dificuldades na negociação.
A busca pela linguagem facilitada fez com que a Folha de S.Paulo decidisse ter uma estrutura única de gestão da audiência, dentro da redação, que, eventualmente, entregue análises para outras áreas. Abaixo da gestão do jornal, há três estruturas ligadas a conteúdo: redação, núcleo de distribuição e audiência e dados. Acreditamos que 0 atual desenho da redação esteja melhor centrado no conceito de redação integrada, uma vez que todas as áreas ligadas a produção e análise de conteúdo estão no mesmo ambiente, trabalham com as mesmas ferramentas e atendem aos mesmos produtos. Segundo Salaverría et. al. (2016a), tal estratégia pode ser compreendida como uma dinâmica da convergência de processos já que vai além da produção e da distribuição de notícias, resultando da reconfiguração cultural das redações, com base em estratégias facilitadoras.

Há distância entre setores da empresa e a redação de Folha, mas é menor, se comparada com a que que existe entre os setores vistos em GaúchaZH. Isso se justifica porque a integração que ocorreu na tomada de decisão a partir das métricas para a reestruturação da gestão da audiência, em 2015, fez com que a convergência também se desse entre a redação e os processos que envolvem audiência. Salaverría (2016a) chama a isso de gestão editorial multiplataforma, um gerenciamento marcado pela coordenação do trabalho da redação com as tarefas dos diferentes meios implicados no processo de produção, distribuição e circulação de conteúdo. 
Como efeito da gestão de métricas, três pontos foram transformados nas redações de GaúchaZH e Folha de S.Paulo: as estruturas das redações; as práticas jornalísticas, que têm de passar pelas demandas do comportamento da audiência; e as estratégias, que incluem a busca por inovação por meio de métricas. Ao analisar tais pontos, percebemos que a concepção do que é audiência pode ser diferente ou limitada, e isso se apresenta como um obstáculo que pode dificultar 0 avanço da estratégia das empresas focadas no digital enquanto modelo de capitalização.

0 desenho da estrutura de GaúchaZH pode ser subdividido em mais de um formato quando se trata da gestão da audiência. Como podemos ver, existe dissipação das informações e dos formatos de métricas, ainda que 0 conteúdo tenha ligação direta com todas as instâncias de gestão de audiência.
Embora a líder de conteúdo centralize a relação entre a redação e as outras áreas, essas outras equipes é que fazem os relatórios de audiência macro - mais lidas e assinaturas - e micro perfil de consumo e comportamento - e, portanto, participam ativamente de decisões estratégicas relacionadas a conteúdo- ou mesmo de não investimento em determinados tipos de notícias. Mais ainda: tomam decisões e constroem planejamentos a partir de métricas de audiência que atuam diretamente na estrutura da redação. A atual configuração da redação foi determinada por estudos de audiência feitos na área de Gestão e Incentivo à audiência e, a partir desse relatório, organizaram-se os horários de cada ator da redação, o número de atores por editoria - e mesmo o corte de determinados atores e a criação de editorias. Entendemos que esse foi o principal efeito da gestão de métricas em GaúchaZH: a estrutura e os modelos de produção são configurados pelo comportamento da

Quadro 1: Subdivisões da gestão da audiência em GaúchaZH em 2017

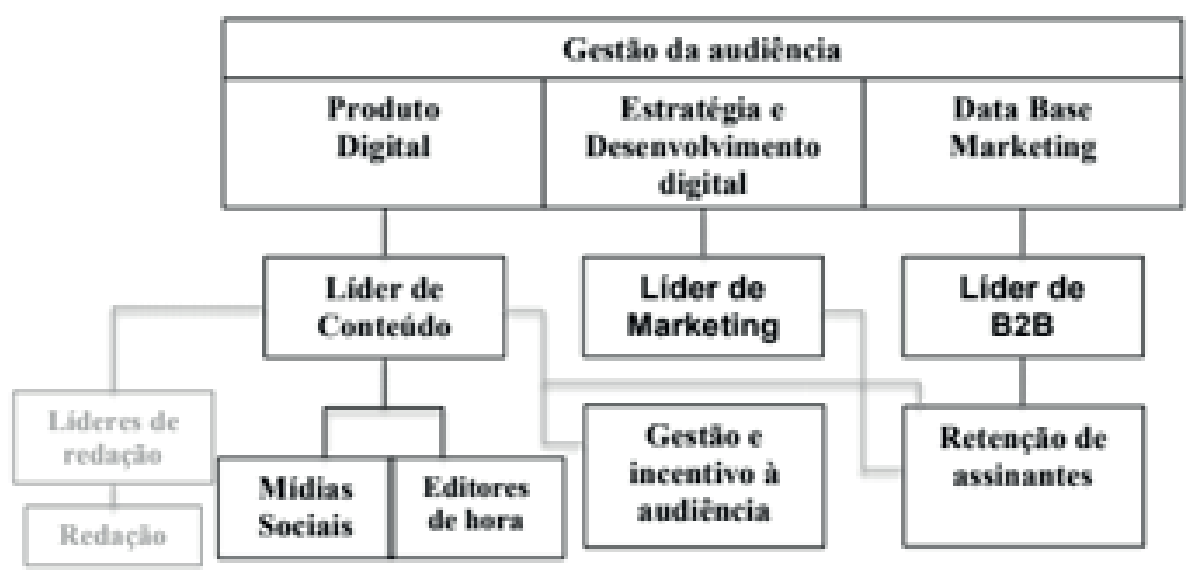


audiência, que é medido por áreas que não estão na redação nem têm formação em jornalismo. 0 modelo da estrutura está mais voltado para um desenho de empresa tradicional e menos de laboratório, em que a prática jornalística poderia ser medida e experimentada de formas menos ligadas ao marketing e, ainda assim, em busca de acessos e assinantes.

Não estamos dizendo, com isso, que o modelo desenhado por GaúchaZH está equivocado. Ele tem dado resultados positivos: as metas de assinatura e de acessos e engajamento foram batidas em 2017, e a gestão de métricas tem buscado inovar no modelo de negócio baseado em jornalismo. Há esforço dessas áreas, como lista Salaverría (2015a), de investigação dos dados - de forma qualitativa e quantitativa -, de desenvolvimento do negócio e de implementação de inovações - estruturais, operacionais e editoriais. Mas há pouco espaço para experimentação. Um exemplo disso são os resultados e ações criadas a partir das métricas. Grande parte das assinaturas de GaúchaZH se dá por conteúdos de esporte e colunistas. Com isso, a gestão de incentivo à audiência criou processos para que os conteúdos tivessem formato adequado para recirculação e, assim, maior número de visualizações, maior engajamento e, por fim, resultasse em novas assinaturas. Em
Esportes, readequou-se toda a grade de horário de trabalho; novos editores digitais foram formados, e os repórteres passaram a receber, diariamente, uma lista com metas de número de publicação. 0 processo foi além do factual, e os repórteres passaram a buscar novas formas de produzir conteúdo para além de partidas, treinos e competições.

Entre os colunistas havia problema maior: o formato dos conteúdos não promovia a recirculação porque boa parte desses colunistas tem de produzir extenso, diário e exclusivo conteúdo para o jornal impresso. Por isso, atores na redação foram transformados em padrinhos de colunistas para que pudessem orientar, acompanhar e redesenhar os conteúdos a fim de tornar as publicações as mais estratégicas possíveis.

Estruturas de laboratório em jornalismo, em redações, atuam como "testadores" de práticas essencialmente jornalísticas conforme o comportamento da audiência9. Em GaúchaZH, a gestão da audiência pulou o passo teste em busca de inovação, por isso não pode ser considerado efetivamente um laboratório. $0 \mathrm{~s}$ resultados de métricas podem virar um modelo de produção com teste direto na redação. A definição do que será produzido quanto a 
conteúdo fica restrito ao Produto Digital e está dentro do escopo de tarefas dos editores de hora.

A atuação da gestão da audiência nas práticas jornalísticas dá-se em formato, em metas de consumo e em metas de produção. A redação tem de, portanto, responder a problemas e solucionálos, oferecendo caminhos com resultados positivos demandados pela gestão da audiência - e esse é mais um efeito das métricas na produção de conteúdo. Essa estrutura apresenta dois problemas: 0 investimento em audiência fez com que as estruturas de análise de métricas crescessem e a redação diminuísse em número de atores. Há um número de pessoas, o qual tem aumentado, para analisar o comportamento da audiência e tomar decisões de planejamento sobre o modelo de negócio, e há cada vez menos gente para executar o objetivo do núcleo de conteúdo da empresa. Além disso, percebemos que não há confiança nos atores que fazem a gestão da audiência. Primeiro, porque estão fora do ambiente da redação e, segundo, porque não têm formação em jornalismo.

\section{Em Folha de S.Paulo encontramos uma} estrutura mais rígida de gestão da audiência, a qual detalhamos a seguir.

Aqui há controle dos dados de audiência por um determinado grupo, que se divide em duas equipes. A líder dessa estrutura é uma só pessoa, e é ela que atende às solicitações sobre audiência de outros setores, que demanda projetos digitais em outros setores e decide a prioridade de tais projetos digitais. Vemos como positivo a estruturação da gestão das métricas dessa forma porque, primeiro, a equipe é formada apenas por jornalistas. Ou seja,

Quadro 2: Estrutura da gestão da audiência em Folha de S.Paulo em 2017

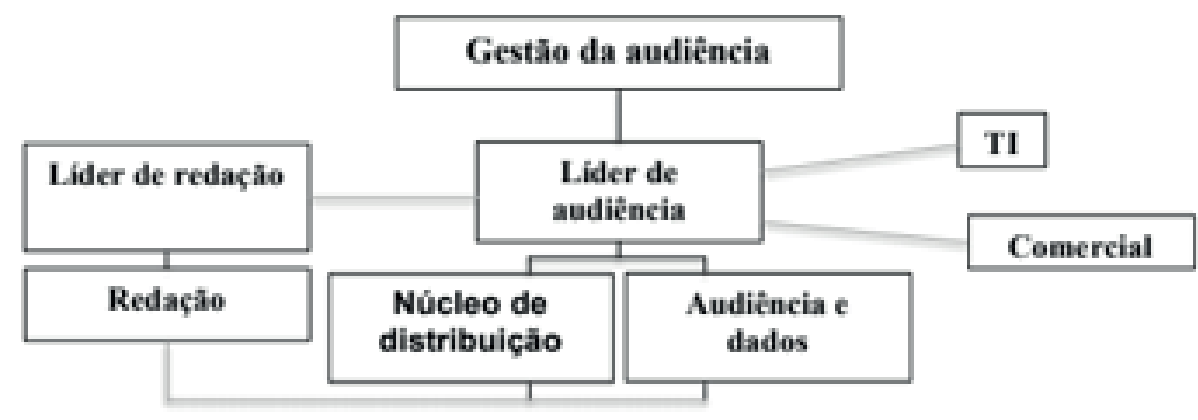

Fonte: Autoria própria.

10 No dia 8 de fevereiro de 2018, a Folha de S. Paulo anunciou, em seu site, que deixou de atualizar sua conta no Facebook após 0 anúncio do site de rede social de que conteúdos de jornalismo profissional terão menos visibilidade. 
a interpretação dos dados é feita a partir de um olhar de quem tem capacidade para entender a ética, os valores e as premissas do jornalismo.

É claro que uma equipe de audiência formada apenas por jornalistas não está livre de erros, mas a interpretação de dados sob um viés jornalístico está de acordo com o valor de inovação transformacional que a Folh a colocou como meta: 0 valor da marca. A editora e toda a redação veem que 0 conteúdo mais lido, em geral, não é política ou economia, em que o jornal reforçou as equipes, mas entretenimento. Com isso, tomaram-se duas decisões: reforçar a equipe de entretenimento a ponto de não deixar descobertos os horários com maior número de visitantes e produzir em escala ampla. A outra decisão foi reforçar as equipes de temas estratégicos para que todas as pessoas na redação trabalhassem nos dois principais produtos, o impresso e o online. Os horários foram modificados, e todos foram treinados para diminuir os processos de edição e aumentar 0 tempo dedicado à produção de conteúdos, que têm resposta da audiência quanto à valorização da marca Folha de S.Paulo.

A atuação da gestão de métricas é, em Folha de S.Paulo, mais processual e estrutural e menos comercial. Há tensões, mas observamos que há entendimento, por parte dos atores da redação, sobre a meta de valor da marca. Os resultados também parecem ser positivos: a empresa se mantém no topo da lista de jornais com maior número de assinantes do país, o que demonstra confiança dessa parcela da audiência na marca. No Facebook, a empresa só perde para G1 no ranking de seguidores (REUTEURS, 2016) ${ }^{10}$.

\section{PROBLEMAS E DIFICULDADES DOS DOIS MODELOS DE GESTÃO DE MÉTRICAS}

A análise e as observações que fizemos na GaúchaZH e na Folha de S.Paulo mostraram-nos que há diferenças e semelhanças importantes no desenho estrutural e estratégico das duas empresas, em termos de gestão de audiência. Utilizam Chartbeat e Google Analytics e dão os mesmos usos a essas ferramentas de medição. Também focam em relatórios quantitativos diários e qualitativos para apoiar o modelo de negócio definido para as empresas.

Dois problemas foram identificados - 0 que nos ajudou a entender 0 que diferencia os dois modelos. 0 primeiro é a demora na tomada de decisão. Quando muitos atores e áreas têm acesso às informações que apoiam a estratégia e podem analisar o comportamento da audiência com diferentes métodos, as decisões passam por mais filtros. Pode ser que mais atores no centro da estratégia ajudem a diminuir falhas, mas quando se trata de notícias hard news, a decisão rápida vai ao encontro da busca da audiência pelo assunto mais atual. 0 segundo problema é a ideia de relatório de produtividade. Em jornais como The New York Times, esse tipo de análise é comum, o que não significa que seja bom. GaúchaZH tem a pretensão de 
implementar em 2018 uma nova avaliação da audiência, uma vez que indica que volume de publicações implica crescimento de audiência. Folha já aplica esse tipo de análise na redação. Um relatório de produtividade pode determinar o fim do problema criado pela automatização, mas pode criar outro: a concorrência interna por demanda de conteúdo que gere mais audiência, produção que segue mais pela lógica da audiência e menos pela jornalística. Acreditamos que um relatório de produtividade sem uma análise sobre o que não é interessante para a audiência cruzada com os objetivos jornalísticos da empresa pode ser bastante ruim para a qualidade jornalística - ainda que obtenham resultados positivos em crescimento de audiência bruta.

Em Folha de S.Paulo, a estrutura mais rígida de análise de audiência tem, na nossa avaliação, pontos negativos e positivos. Quando a redação tem acesso a dados de audiência, mas não de forma fácil, pode ter concepções diferentes da área de gestão sobre o público e, além disso, não tem acesso claro ao que está sendo analisado como a produtividade - e os resultados aplicados das análises - como as mudanças estruturais. A redação recebe formação para trabalhar com dados sobre a audiência, mas não participa de análises e decisões estratégicas que passam pela audiência. 0 relatório de produtividade em Folha de S.Paulo também tem um ponto positivo: 0 documento é feito para que a redação não invista tempo em produções mal lidas.
Os problemas principais desses dois modelos, para nós, vão um ao encontro do outro: concentração (Folha de S.Paulo) e dissipação de informações (GaúchaZH). A concentração faz com que os atores da redação trabalhem focados no objetivo qualidade em jornalismo, e com que a informação principal sobre 0 comportamento da audiência esteja nas mãos da equipe de gestão de métricas. Portanto, é dela a responsabilidade de compartilhar os dados sobre a audiência. Folha de S.Paulo faz isso de forma analíticainterpreta os dados e, então, toma uma decisão estratégica que impactará a produção. Essa informação analítica é compartilhada na forma de orientação à redação, o que pode gerar um novo problema: uma redação pouco inovadora do ponto de vista digital.

Folha de S.Paulo sabe da necessidade de identificar e promover talentos inovadores diante do futuro, ao mesmo tempo em que precisa manter estruturas estabelecidas (SALAVERRÍA, 2016b) e, assim, criou uma estrutura de gestão de métricas menos flexível. Garante, com isso, qualidade no produto jornalístico, controle sobre dados e concentração da estratégia sobre a estrutura da empresa, formato de produção, organização editorial e fins comerciais do comportamento da audiência. Perde, no entanto, flexibilidade ao não trabalhar de forma experimental. 0 caminho que Folha de S.Paulo tomou parece ter mais eficácia do ponto de vista jornalístico 
porque mantém a prioridade na qualidade jornalística - investigação, busca pela verdade, questionamentos (de acordo com as premissas empresariais) - mas falta qualificar a equipe quanto ao ideal laboratorial para fazer a gestão da inovação e buscar soluções inovadoras seguindo os objetivos do modelo jornalístico - por meio dos resultados das métricas. É um grupo que pode ter a formação exigida pela empresa, mas que critique os dados, entenda que decisões devem ser tomadas mais rapidamente, quais projetos precisam de produção e avaliação a longo prazo e, principalmente, encontre ou crie caminhos de distribuição que vão além de sites de redes sociais.

No modelo produto, o problema da dissipação da informação cria a automatização da produção - 0 que vai totalmente de encontro à busca por inovação. Em GaúchaZH, o modelo é interessante do ponto de vista comercial e menos do jornalístico. Trabalha-se de acordo com o comportamento da audiência, mas, assim como ocorreu em The New York Times (2017, online), "a maioria dos departamentos não tomou decisões sobre quem é o público principal e quais formas jornalísticas são uma prioridade (e quais não são)". A empresa tem o escopo de tarefas por ator, mas percebemos que, ainda assim, no que diz respeito à gestão de métricas, isso se confunde. Há repórteres trabalhando com dados sobre a audiência abertos no computador no formato consolidado e no formato tempo real, sem uma estratégica específica ou orientada.

Há editores digitais e de impresso monitorando o comportamento da audiência também sem homogeneidade ou orientação. Os editores da hora fazem orientações conforme o tempo real e repetem relatórios consolidados enviados por outros atores de gestão de métricas. Enquanto isso, a equipe de gestão de métricas está dividida em três espaços distintos, e há pouca clareza sobre a proximidade entre eles. 0s relatórios diários são enviados de forma automatizada, sem análise sobre cada um dos resultados. Espera-se que os atores da redação façam essa análise, mas isso ocorre com pouca frequência. Ainda que o modelo de produto aplicado em GaúchaZH atue orientado para a inovação, a dissipação dos atores e das informações atrapalha. Entendemos que a união dos atores de gestão de métricas em um mesmo setor, com uma só liderança, que apoie atores estratégicos da empresa e incorpore atores que trabalhem orientados para inovação por meio da gestão de métricas seria mais adequada para 0 modelo dessa empresa.

\section{A organização do modelo de produto é mais} complexa porque a empresa quer atuar orientada para o comercial, mas, como se trata de um modelo de negócio jornalístico, precisa manter premissas do modelo jornalístico. Organizar os atores de gestão estratégica e analítica de métricas de audiência com formação em jornalismo e mesclar com outros atores, em um 
formato de laboratório, pode ser o caminho para encontrar e implementar soluções inovadoras à empresa. Primeiro, entendemos que é preciso redesenhar a estrutura de gestão de métricas com o objetivo de pôr fim à dissipação e automatização dos resultados sobre o comportamento da audiência. Depois, é preciso reorganizar o escopo de tarefas dos atores desse grupo e implementar o objetivo qualidade jornalística aos que farão analises qualitativas dos dados (e aqui seguir a premissa da formação em jornalismo pode ser 0 melhor caminho) e, por fim, ter um grupo de gestão de métricas que atue em formato laboratorial.

\section{UMA PROPOSTA DE MODELO}

Quando propusemos a atuação de gestão de métricas em formato laboratorial -para 0 modelo jornalístico e para o modelo de produto -indicamos que é preciso atuar com capacidade para atrair audiências e gerar negócios a partir delas (SALAVERRÍA, 2015a). 0s laboratórios de inovação em jornalismo podem ser a forma ideal de crescer diante dos sites de redes sociais e buscadores e combater problemas de confiabilidade. 0 desenho de um laboratório de inovação em jornalismo deveria considerar:

\section{- Organização dos atores: é preciso escolher} quem fará parte dessa equipe pela capacidade de empreendimento e coordenação das estratégias editoriais e comerciais para que, além de se fazer bem o que se fazia, descubram-se novas áreas de oportunidade (SALAVERRÍA, 2015a). Se 0

objetivo é qualidade jornalística, deve-se priorizar o conhecimento na área e a competência para trabalhar analiticamente os dados sobre 0 comportamento da audiência. Se o objetivo é produto, entendemos que a formação tem de ser jornalística porque, antes de tudo, jornalismo é informar com qualidade. No entanto, a equipe pode ter atores focados em distribuição e comercialização para que, em conjunto, criem e apoiem setores que não apenas inflem a redação.

- Organização do espaço: uma empresa que tem o jornalismo como modelo de negócio tem de ter seu laboratório dentro da estrutura da redação para definir o papel de cada ator e acompanhar o empacotamento e a distribuição dos produtos. Um laboratório de inovação em jornalismo deve atuar junto com a redação.

- Definição do escopo de tarefas: um laboratório de inovação em jornalismo precisa ser 0 responsável pelas estratégias da empresa junto com a alta administração. Para isso, precisa definir quem faz 0 que em relação às métricas, à produção, ao empacotamento e à distribuição de conteúdo.

- Definição das métricas: a gestão sobre os dados do comportamento da audiência deve apoiar decisões estratégicas; portanto, entendese que esse processo não pode ser automatizado. A organização do processo de obtenção de resultados por meio de diferentes ferramentas 
definirá como o comportamento será medido, orientando, assim, como as medições serão feitas (e por quem) e implementando, então, sistemas de análise que apoiem decisões rápidas e decisões estratégicas. Isso deveria acontecer, no contexto de convergência, como indica Jenkins (2006), em que as empresas têm de estar preparadas para produzir e analisar as métricas através do fluxo contínuo de conteúdo (concorrência), cooperação de múltiplos mercados (competências diversas) e comportamento migratório dos públicos. Automatizar e concentrar os dados e as decisões sobre o comportamento da audiência, portanto, são erros que vão de encontro com a ideia de convergência midiática, jornalística e de métricas porque desintegram a redação.

\section{- Definição das análises: os métodos} quantitativos de gestão de métricas são necessários e importantes para a busca de soluções estratégicas rápidas. Atua-se em um determinado ponto do conteúdo e resolve-se um problema. No entanto, a estratégia de uma empresa não pode estar baseada em decisões rápidas. Quando se automatizam os dados perde-se mais ainda: os atores que deveriam apoiar suas decisões de produção de conteúdo constroem uma imagem sobre a audiência que pode ser diferente dos objetivos da empresa.

Um laboratório de inovação tem atores que atuam na organização e distribuição das análises quantitativas, mas, principalmente, tem sistematização, competência e liberdade para construção e organização de análises qualitativas. Isso inclui relatórios de produtividade que podem encontrar os problemas da redação e atuar pontualmente para solução, com treinamentos mais práticos (e menos teóricos), contratações de atores que possam também criar conteúdo estratégico (com bom empacotamento e distribuição).

Quadro 3: Proposta de estrutura de empresa de jornalismo na internet

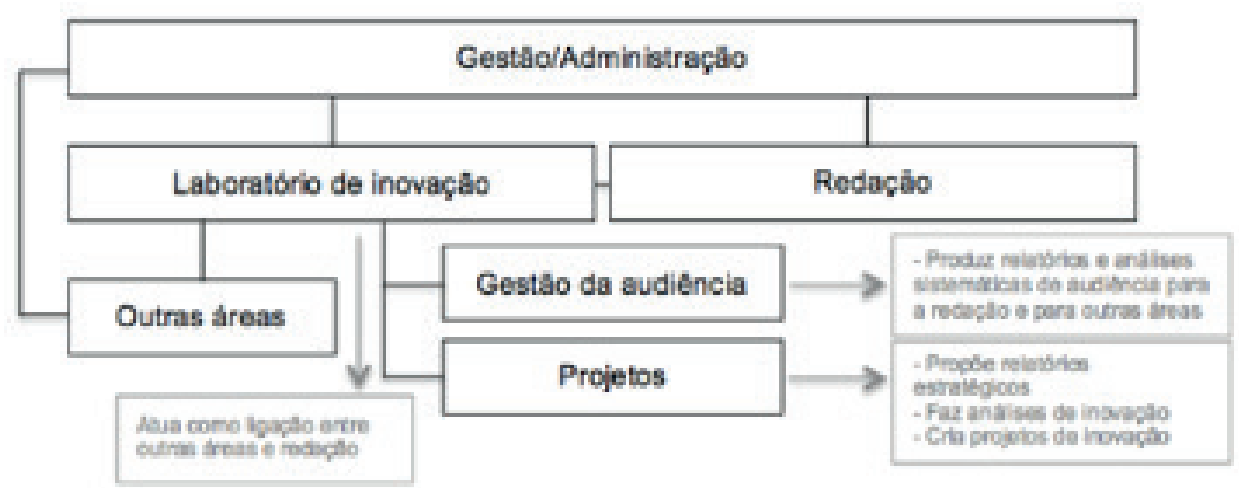


Portanto, nossa proposta é de um desenho estratégico de redação que siga premissas do jornalismo e que atue como apoio a setores estratégicos da empresa:

\section{Considerações finais}

As análises nas estruturas de gestão da audiência das duas empresas revelam-nos a carência de um modelo sustentável de laboratório para experimentar novos processos, ainda que nos mostrem que GaúchaZH e Folha de S.Paulo utilizam lógicas de laboratórios de inovação, organizando ideias, competências e recursos da empresa (SALAVERRÍA, 2015a) - o que pode levar a rupturas, tensões, remodelações e criações de novos produtos e/ou processos. Chegar a uma estrutura de laboratório de inovação parece ser um caminho longo que 0 jornalismo tradicional no Brasil ainda não ousou ou ao qual não teve condições de chegar. No entanto, as organizações jornalísticas precisam de audiência e, assim, criaram áreas de gestão sobre os dados que refletem o comportamento dos leitores. São estruturas necessárias, mas ainda carecem de amadurecimento. A forma como os dados chegam à redação também muda a lógica da produção, e esse distanciamento no gerenciamento faz com que a percepção da audiência entre redação e gestão da audiência não seja linear também.

Trabalhos como o de Canavilhas (2016) mostramnos que editores e repórteres problematizam 0 novo esquema de produção de notícias na internet e criam, assim, problemas sobre a significação da audiência dentro das redações. Há cerca de duas décadas, assim como fizeram até então, editores e repórteres tinham controle sobre suas atuações e sobre a redação. No entanto, desde que a internet passou a ser uma plataforma de distribuição de conteúdo - e ganhou importância fundamental no mercado jornalístico em todo o mundo os mecanismos de negociação entre repórteres, editores, executivos, analistas, tecnoatores e audiência alteraram a lógica da operação. "Em disputa está o controle das rotinas e dos produtos, bem como a própria noção de notícia”, explica Canavilhas (2016, p. 3).

Nas redações analisadas por Tandoc Jr. (2014, p. 567), 0 autor percebeu instabilidade na institucionalização do uso de métricas exatamente por implicar mudança na interação entre jornalistas e audiência, entrega de conteúdo e acesso de dados. Essa tensão pode ser vista na diferença de atuação entre, principalmente, editores que trabalham em distintos dispositivos. 0 online, segundo o autor, é considerado um viciado em números e painéis de análise. Usando a metáfora do uso de drogas, Tandoc Jr. diz que 0 ator online é tratado dessa maneira porque ele tem potencial para perder 0 controle editorial e, então, não funciona mais normalmente. 0 normal, para 0 editor off-line, é entender a audiência como uma segunda classe, como alguém que não sabe fazer as conexões da maneira que 0 editor considera correta. 
Percebe-se que, ainda que os modelos de gestão de métricas tenham diferenças importantes entre GaúchaZH e Folha de S.Paulo, a estratégia sobre a operação com os dados é bastante próxima. As duas empresas usam as mesmas ferramentas de gestão da audiência e têm objetivos parecidos no trato dos dados provenientes deles. De acordo com Petre (2015), a cultura organizacional molda 0 uso de métricas, e isso quer dizer que a utilização dos dados sobre o comportamento da audiência como base para remodelação estrutural pode demonstrar que a cultura organizacional ainda não aceita bem tudo o que a cultura digital implica, ainda que as empresas estejam apoiando seus modelos de negócio nos produtos digitais. Isso pode levar à moldagem superficial das informações sobre 0 comportamento da audiência, uma vez que, como explica Petre (2015), no lugar de ter sua autoridade diminuída pelas métricas, editores de tempo controlam circulação e interpretação na sala de redação, atendendo assim a finalidades editoriais e gerenciais que já existiam anteriormente.

Podemos concluir, com isso, que a gestão da audiência pode produzir relatórios que apontam falhas e erros e, principalmente, indicar gostos e comportamentos da audiência que servem para que os atores da redação criem ou revisem suas concepções de audiência, a chamada audiência presumida, relatada por Canavilhas (2016). Ainda assim, essa gestão acaba tendo dificuldades para disseminar a cultura da participação de forma homogênea na redação, mas, principalmente, encontra obstáculos ou busca não abrir claramente dados para que a própria redação compreenda 0 que está sendo analisado e o que não está. Por fim, nossa análise dos modelos de gestão de métricas de GaúchaZH e Folha de S.Paulo também não tem um caráter de interpretação conclusiva. Aqui reunimos alguns pontos que podem ser repensados e indicamos operações que podem ser testadas em outros jornais.

\section{Referências}

AQUINO BITTENCOURT, Maria Clara. Convergência midiática e redes digitais: modelo de análise para pesquisas em comunicação. Curitiba: Editora Appris, 2017.

CANAVILHAS, João; et. al. Jornalistas e tecnoatores: a negociação de culturas profissionais em redações online. Revista Famecos. Porto Alegre, v. 23, n. 3, 2016.

HAAK, Bregtje van der. PARKS, Michael; CASTELLS, Manuel. The future of journalism: networked journalism. International jornal of communication. $6,2012$.

HADDAD, Evelyn Witt. Inovação tecnológica em Schumpeter e na ótica neo-schumpeteriana.

Trabalho de conclusão de curso (Graduação em Ciências Economicas). Faculdade de Ciências Econômicas, Universidade Federal do Rio Grande do Sul, Porto Alegre, 2010.

\section{HEINRICH, Ansgard. Network journalism:} Journalistic Practice in Interative Spheres. New York: Routledge, 2011.

JENKINS, Henry. Convergence Culture: Where 0ld and New Media Collide. New York: NYU Press, 2006. .; FORD, Sam; GREEN, Joshua. Cultura da Conexão: criando valor e significado por meio da mídia propagável. Editora Aleph: São Paulo, 2014. 
KUNG, Lucy. Innovators in digital news. London / New York: I.B.Tauris \& Co; Reuters Institute for the Study of Journalism, 2015.

LEVY, David A. L. Foreword. Digital News Report In: Reuters Institute. 2016. 2016. Disponível em: < http:// reutersinstitute.politics.ox.ac.uk/sites/default/files/ Digital-News-Report-2016.pdf> . Acesso em: 02/04/18 LÉVY, Pierre. Tecnologias da Inteligência. São Paulo: editora 34, 1993.

NEW YORK TIMES. Innovation. March 24, 2014.

Disponível em: < http://mashable.com/2014/05/16/fullnew-york-times-innovation-report/\#a7wJMG9Hakq2>. Acesso em: 02/04/18

Journalism That Stands Apart. Jan,

2017. Disponível em: < https://www.nytimes.com/ projects/2020-report/?mcubz $=0>$. Acesso em: 02/04/18.

OUDEN, den Elke. Meaning Innovation. In: OUDEN, den Elke. Innovation Design. Creating Value for People, Organizations and Society. Londres: Springer-Verlag, 2012 ..

\section{PEW RESEARCH CENTER. State of the News Media}

2016. Disponível em: <www.journalism.org/2016/06/15/ state-of-the-news-media-2016/> . Acesso em: 02/04/18.

. State of the News Media 2017. Disponível

em: < http://www.journalism.org/fact-sheet/digitalnews/>. Acesso em: 02/04/18

PETRE, Caitlin. The Traffic Factories: Metrics at Chartbeat, Gawker Media, and The New York Times.

Tow Center for Digital Journalism. 7 maio 2015.

Disponível em: < http://towcenter.org/research/trafficfactories/>. Acesso em: 02/04/18

REUTERS INSTITUTE. Digital News Report 2017.

Disponível em: < http://reutersinstitute.politics.ox.ac. uk/sites/default/files/Digital-News-Report-2017.pdf> . Acesso em: 02/04/18

ROBINSON, James. Audiences for Journalism:
Perception and Reality. Tow Center for Digital journalism. 21 out. 2016. Disponível em: < http:// towcenter.org/audiences-for-journalism-perceptionand-reality/>. Acesso em: 02/04/18

SALAVERRÍA, Ramon. Convergencia de los médios. Revista Chasqui. N. 81, mar. 2003. Disponível: http://chasqui.ciespal.org/index.php/chasqui/article/ view/1471 Acesso em: 02/04/18 Innovar en prensa: dónde, cómo y por qué.

In: AED. El Libro Blanco de la Prensa Diaria 2015. Madrid: Asociación de Editores de Diarios Españoles (AEDE), 2015a.

. Los labs como fórmula de inovación en los medios. El professional de la información. v. 24, n. 4, 2015b.

Periodismo disruptivo. Dilemas y estrategias para la innovación. Buenos Aires: La crujía, $2015 \mathrm{c}$. La innovación y los cibermedios: los labs. In: CHALEZQUER, Charo Sábada; AVILÉS, José Alberto García; MARTÍNEZ-COSTA; María del Pilar. (coord.). Innovación y desarollo de los cibermedios en España. Pamplona: Ediciones Universidad de Navarra, 2016a.

; et. al. Convergence Culture in European

Newsrooms. Comparing editorial strategies for crossmedia news production in six countries. Journalism Studies. 11 out. $2016 \mathrm{~b}$.

WOLF, Mauro. Teorias da Comunicação. 5 ed. São Paulo: Martins Fontes, 1999. 


\begin{tabular}{|c|c|}
\hline $\begin{array}{l}\text { Innovation and audience: the cases } \\
\text { of Gaúcha ZH and Folha de S.Paulo }\end{array}$ & $\begin{array}{l}\text { Innovación y audiencia: los casos } \\
\text { de GaúchaZH y Folha de S.Paulo }\end{array}$ \\
\hline $\begin{array}{l}\text { Abstract } \\
\text { This article presents part of the results of a research } \\
\text { that tried to understand the strategic decisions } \\
\text { of GaúchaZH and Folha de S.Paulo companies that } \\
\text { are affected by audience metrics. Specific sectors } \\
\text { are identified in both companies, responsible for } \\
\text { managing metrics and making decisions based on } \\
\text { users' behaviors, guiding business resolutions from } \\
\text { journalistic production. We present part of the results } \\
\text { of the research on these sectors, since they are } \\
\text { responsible for problem deliberation and exploration } \\
\text { of new opportunities based on the metrics that } \\
\text { they manage and with focus on innovation. } \\
\text { Keywords } \\
\text { Innovation. Audience. Journalism. }\end{array}$ & $\begin{array}{l}\text { Resumen } \\
\text { Este artículo presenta parte de los resultados } \\
\text { de una investigación que buscó entender las } \\
\text { decisiones estratégicas de las empresas GaúchaZH } \\
\text { y Folha de S.Paulo que son afectadas por las } \\
\text { métricas de audiencia. Los sectores específicos son } \\
\text { identificados en las dos emprełsas, responsables } \\
\text { de gestionar métricas y originar decisiones a partir } \\
\text { de los comportamientos de los usuarios, orientando } \\
\text { resoluciones de negocios desde la producción } \\
\text { periodística. Presentamos parte de los resultados } \\
\text { de la investigación sobre estos sectores, ya que son } \\
\text { responsables de la deliberación de problemas } \\
\text { y explotación de nuevas oportunidades con base en } \\
\text { las métricas que gestionan y con foco en la innovación. } \\
\text { Palabras-clave } \\
\text { Innovación. Audiência. Periodismo. }\end{array}$ \\
\hline
\end{tabular}




\section{Expediente}

A revista E-Compós é a publicação científica em formato eletrônico da Associação Nacional dos Programas de Pós-Graduação em Comunicação (Compós). Lançada em 2004, tem como principal finalidade difundir a produção acadêmica de pesquisadores da área de Comunicação, inseridos em instituições do Brasil e do exterior.

\section{E-COMPÓS I www.e-compos.org.br I E-ISSN 1808-2599}

Revista da Associação Nacional dos Programas de Pós-Graduação em Comunicação. Brasília, v.21, n.3, set/dez. 2018. A identificação das edições, a partir de 2008, passa a ser volume anual com três números. Indexada por Latindex I www.latindex.unam.mx

\section{CONSELHO EDITORIAL}

Ada Cristina Machado Silveira, Universidade Federal de Santa Maria, Brasi Alda Cristina Silva da Costa, Universidade Federal do Pará, Brasil Alfredo Luiz Paes de Oliveira Suppia, Universidade Estadual de Campinas, Brasil Ana Carolina Rocha Pessôa Temer, Universidade Federal de Goiás, Brasil Ana Regina Barros Rego Leal, Universidade Federal do Piauí, Brasil André Luiz Martins Lemos, Universidade Federal da Bahia, Brasil Angela Cristina Salgueiro Marques, Universidade Federal de Minas Gerais, Brasil Ângela Freire Prysthon, Universidade Federal de Pernambuco, Brasil Anna Cristina Pertierra, Western Sidney University, Austrália Antonio Carlos Hohlfeldt, Pontifícia Universidade Católica do Rio Grande do Sul, Brasi Arthur Ituassu, Pontifícia Universidade Católica do Rio de Janeiro, Brasil Bruno Campanella, Universidade Federal Fluminense, Brasil Bushra Hameedur Rahman, University of the Punjab, Paquistão, Paquistão Cárlida Emerim, Universidade Federal de Santa Catarina, Brasil Carlos Del Valle Rojas, Universidad de La Frontera, Chile Carlos Eduardo Franciscato, Universidade Federal de Sergipe, Brasil Cláudio Novaes Pinto Coelho, Faculdade Cásper Líbero, Brasil Danilo Rothberg, Universidade Estadual Paulista, Brasil Denise Tavares, Universidade Federal Fluminense, Brasil Diógenes Lycarião, Universidade Federal do Ceará, Brasil Dóris Martínez Vizcarrondo, Universidad de Puerto Rico Mayagüez, Porto Rico Eduardo Vicente, Universidade de São Paulo, Brasil

Eliza Bachega Casadei, Escola Superior de Propaganda e Marketing - SP, Brasil Elvira Gomes dos Reis Freitas, Universidade de Cabo Verde, Cabo Verde Eneus Trindade, Universidade de São Paulo, Brasil Erick Felinto de Oliveira, Universidade do Estado do Rio de Janeiro, Brasil Erick Torrico, Universidad Andina Simón Bolívar, Bolívia, Bolívia Erly Vieira Júnior, Universidade Federal do Espírito Santo, Brasil Fabio La Rocca, Université Paul-Valéry Montpellier 3, França Fernando Firmino da Silva, Universidade Federal da Paraíba, Brasil Francisco de Assis, FIAM-FAAM Centro Universitário, Brasil Francisco Elinaldo Teixeira, Universidade Estadual de Campinas, Brasil Francisco Gilson Rebouças Pôrto Junior, Universidade Federal do Tocantins, Brasil Francisco Sierra Caballero, CIESPAL, Equador Frederico de Mello Brandão Tavares, Universidade Federal de Ouro Preto, Brasil Gabriela Reinaldo, Universidade Federal do Ceará, Brasil Germán Rey Beltrán, Universidad Nacional de Colombia, Colômbia Gilson Vieira Monteiro, Universidade Federal do Sul da Bahia, Brasil Gustavo Daudt Fischer, Universidade do Vale do Rio dos Sinos, Brasil Gustavo Hernández Díaz, Universidad Central de Venezuela, Venezuela Heidi Figueroa Sarriera, Universidad de Puerto Rico, Porto Rico Ignacio Aguaded, Universidad Huelva, Espanha Inesita Soares de Araújo, FIOCRUZ, Brasil Itania Maria Mota Gomes, Universidade Federal da Bahia, Brasil Jiani Adriana Bonin, Universidade do Vale do Rio dos Sinos, Brasi João Carlos Ferreira Correia, Universidade da Beira Interior, Portugal Jonathan Cohen, University of Haifa, Israel José Afonso da Silva Junior, Universidade Federal de Pernambuco, Brasil José Luiz Aidar Prado, Pontifícia Universidade Católica de São Paulo, Brasil Josette Maria Monzani, Universidade Federal de São Carlos, Brasil Juçara Gorski Brittes, Universidade Federal de Ouro Preto, Brasil Julián Durazo Hermann, Université du Québec à Montreal, Canadá Juliana Freire Gutmann, Universidade Federal da Bahia, Brasil
Karla Yolanda Covarrubias, Universidad de Colima, México Laura Loguercio Cánepa, Universidade Anhembi Morumbi, Brasil Leonel Azevedo de Aguiar, Pontifícia Universidade Católica do Rio de Janeiro, Brasil Leticia Cantarela Matheus, Universidade do Estado do Rio de Janeiro, Brasil Ling Chen, Hong Kong Baptist University, China Luciana Coutinho Souza, Universidade de Sorocaba, Brasil Marcel Vieira Barreto Silva, Universidade Federal da Paraíba, Brasil Marcia Tondato, Escola Superior de Propaganda e Marketing, Brasil Márcio Souza Gonçalves, Universidade do Estado do Rio de Janeiro, Brasil Maria Ataide Malcher, Universidade Federal do Pará, Brasil Maria das Graças Pinto Coelho, Universidade Federal do Rio Grande do Norte, Brasi Maria Elena Hernández Ramirez, Universidad de Guadalajara, México Maria Elisabete Antonioli, Escola Superior de Propaganda e Marketing - SP, Brasil Maria Teresa Quiroz, Universidad de Lima, Peru Marialva Carlos Barbosa, Universidade Federal do Rio de Janeiro, Brasil Marina Poggi, Universidad Nacional de Quilmes, Argentina Marli Santos, Faculdade Cásper Líbero, Brasil Mateus Yuri Passos, Universidade Metodista de São Paulo, Brasil Mauricio Mario Monteiro, Universidade Anhembi Morumbi, Brasil, Brasil Mayka Castellano, Universidade Federal Fluminense, Brasil Mirta Varela, Universidad de Buenos Aires, Argentina

Mozahir Salomão Bruck, Pontifícia Universidade Católica de Minas Gerais, Brasil Neyla Graciela Pardo Abril, Universidad Nacional de Colombia, Colômbia Nísia Martins Rosario, Universidade Federal do Rio Grande do Sul, Brasil Olga Guedes Bailey, Nottingham Trent University, Reino Unido Paolo Demuru, Universidade Paulista, Brasil

Paolo Peverini, LUISS, Itália

Paško Bilić, Institute for Development and International Relations, Croácia Paula Melani Rocha, Universidade Estadual de Ponta Grossa, Brasil Potiguara Mendes Silveira Jr, Universidade Federal de Juiz de Fora, Brasil Rafael Cardoso Sampaio, Universidade Federal do Paraná, Brasil Rafael Tassi Teixeira, Universidade Tuiuti do Paraná, Brasil Regiane Lucas de Oliveira Garcêz, Universidade Federal de Minas Gerais, Brasil Regiane Regina Ribeiro, Universidade Federal do Paraná, Brasil Renata Pitombo Cidreira, Universidade Federal do Recôncavo da Bahia, Brasil Renato Essenfelder, Escola Superior de Propaganda e Marketing, Brasil Roberto Elísio dos Santos, Universidade Municipal de São Caetano do Sul, Brasil Robson Borges Dias, Universidade Católica de Brasília (UCB), Brasil Rodolfo Rorato Londero, Universidade Estadual de Londrina, Brasil Rosario Sanchéz Vilela, Universidad Católica del Uruguay, Uruguai Roseli Figaro, Universidade de São Paulo, Brasil Saima Saeed, Jamia Millia Islamia, India Sara Brandellero, Leyden University, Holanda Simone Maria Andrade Pereira de Sá, Universidade Federal Fluminense, Brasil Sônia Caldas Pessoa, Universidade Federal de Minas Gerais, Brasil Sun Sun Lim, Singapore University of Technology and Design, Singapura Tatiana Oliveira Siciliano, Pontifícia Universidade Católica do Rio de Janeiro, Brasil Thaïs de Mendonça Jorge, Universidade de Brasília, Brasil Valquiria Michela John, Universidade Federal do Paraná, Brasil Vicky Mayer, Tulane University, Estados Unidos da América do Norte Yamile Haber Guerra, Universidad de Oriente, Cuba 


\section{CONSELHO CIENTÍFICO}

Cristiane Freitas Gutfreind, Pontifícia Universidade Católica do Rio Grande do Sul, Brasil I Eduardo Antonio de Jesus, Universidade Federal de Minas Gerais, Brasil I Eduardo Morettin, Universidade de São Paulo, Brasil I Irene de Araújo Machado, Universidade de São Paulo, Brasil

\section{COMISSÃO EDITORIAL}

Igor Pinto Sacramento, Universidade Federal do Rio de Janeiro, Brasil I Kelly Cristina de Souza Prudencio, Universidade Federal do Paraná, Brasil | Miriam de Souza Rossini, Universidade Federal do Rio Grande do Sul, Brasil

\section{EDITORES ASSOCIADOS}

Rafael Grohmann, Faculdade Cásper Líbero, Brasil I Thaiane Moreira de Oliveira, Universidade Federal Fluminense, Brasil

\section{CONSULTORES AD HOC}

Ada Machado, Universidade Federal de Santa Maria, Brasil | Ana Carolina Escosteguy, Universidade Federal de Santa Maria, Brasil | Andrea França, Pontifícia Universidade Católica do Rio de Janeiro, Brasil | Ariane Holzbach, Universidade Federal Fluminense, Brasil | Benjamim Picado, Birkbeck College, Inglattera | Bruno Souza Leal, Universidade Federal de Minas Gerais, Brasil I Eduardo Morettin, Universidade de São Paulo, Brasil I Felipe Trotta, Universidade Federal Fluminense, Brasil | Francisco Rüdiger, Pontifícia Universidade Católica do Rio Grande do Sul, Brasil | Gislene da Silva, Universidade Federal de Santa Catarina, Brasil | Inês Vitorino, Universidade Federal do Ceará, Brasil I Isaltina Gomes, Universidade Federal de Pernambuco, Brasil I Jairo Ferreira, Universidade do Vale do Rio dos Sinos, Brasil I Karina Janz, Universidade Estadual de Ponta Grossa, Brasil I Kati Caetano, Universidade Tuiuti do Paraná, Brasil I Lilian França, Universidade Federal do Sergipe, Brasil I Liziane Guazina, Universidade de Brasília, Brasil I Márcio de Vasconcellos Serelle, Pontifícia Universidade Católica de Minas Gerais, Brasil I Marta Maia, Universidade Federal de Ouro Preto, Brasil I Maurício de Bragança, Universidade Federal Fluminense, Brasil I Nina Velasco e Cruz, Universidade Federal de Pernambuco, Brasil | Norval Baitello Jr., Pontifícia Universidade Católica de São Paulo, Brasil | Pedro Guimarães, Universidade do Estado do Rio de Janeiro, Brasil | Priscilla Perazzo, Universidade Municipal de São Caetano do Sul, Brasil I Sofia Zanforlin, International Association of Media and Communication Research, Estados Unidos I Talitha Ferraz, Escola Superior de Propaganda e Marketing, Brasil I Tattiana Teixeira, Universidade Federal de Santa Catarina, Brasil I Victa de Carvalho Pereira da Silva, Universidade Federal do Rio de Janeiro, Brasil

\section{EQUIPE DE EDITORAÇÃO}

ASSISTENTE EDITORIAL Marcio Telles | REVISÃO DE TEXTOS Fátima Áli | EDITORAÇÃO ELETRÔNICA Roka Estúdio

\section{COMPÓS I www.compos.org.br}

Associação Nacional dos Programas de Pós-Graduação em Comunicação

Presidente

Marco Roxo

Programa de Pós-Graduação em Comunicação - UFF

marcos-roxo@uol.com.br

Vice-Presidente

Isaltina Gomes

Programa de Pós-Graduação em Comunicação - UFPE

isaltina@gmail.com

Secretária-Geral

Gisela Castro

Programa de Pós-Graduação em Comunicação

e Práticas de Consumo - ESPM

castro.gisela@gmail.com

CONTATO I revistaecompos@gmail.com 